\title{
Gambaran Aktivitas Fisik Pada Individu Obesitas Di Wilayah Kerja Puskesmas Sidorejo Kidul Salatiga
}

\author{
Daniel Tri Angga*, Kukuh Pambuka Putra, Kristiawan P.A. Nugroho
}

\begin{abstract}
Background: Obesity is one of the health problems related to the prevalence of cardiometabolic disease. WHO states that obesity is a complex, serious problem experienced by all age groups, ranging from children, adults to the elderly. Obesity must be treated immediately because it has the potential to become a health problem (1). In obese patients who have a Body Mass Index (BMI)> $30 \mathrm{~kg} / \mathrm{m} 2$ will increase the risk of Coronary Heart Disease (CHD), both men and women. The American Heart Association (AHA) classifies obesity as a risk factor for coronary heart disease. Someone with central Obesity (upper body obesity) will be easily exposed to the risk of heart disease and other metabolic diseases known as metabolic syndrome compared with ginoid obesity (lower body obesity) is very small will be the risk of metabolic disease and coronary heart disease.
\end{abstract}

Objective: The purpose of the study to determine the description of community behavior seen from the point of view of physical activity that became one of the causes of obesity in Salatiga City.

Method: This research method is descriptive quantitative with observation approach. The population in this study is the people who have checked themselves to the Puskesmas Sidorejo Kidul, each from the scope of work area of Sidorejo Kidul Puskesmas. The inclusion criteria applied were: 1) people living in the working area of pusidmas sidorejo kidul, 2) aged 40 years and over, 3) IMT more than 27,0. Variables studied in this research is the intensity of physical activity and BMI. The instrument used to measure the intensity of physical activity is the Global Physical Activity Questionnaire (GPAQ). The interview was conducted to identify the understanding of the community in the work area of Sidorejo Kidul Public Health Center towards obesity and physical activity.

Result: After all the data collected the results of the research were carried out by analyzing the data by data reduction, data presentation, drawing conclusions, and verification. Setelah semua data terkumpul hasil penelitian dilakukan dengan cara analisa data dilakukan dengan reduksi data, penyajian data, penarikan kesimpulan, dan verifikasi.

Conclusion: The physical activity of the elderly in the working area of the Puskesmas Sidorejo in the city of Salatiga, based on the Global Physical Activity Questionnaire (GPAQ) calculation is included in the medium category of $50 \%$ with physical activities generally carried out by housewives such as sweeping, mopping, cooking, and wash. As many as $15 \%$ of the elderly are in the category of low physical activity and the rest are included in the high category of $35 \%$.

Keyword: Physical activity, Obesity

Afiliasi Penulis

Universitas Kristen Satya Wacana

Korespondensi kepada

D.T. Angga

482014011@student.uksw.edu 


\section{Intisari}

Latar Belakang: Obesitas merupakan salah satu masalah kesehatan yang berkaitan dengan prevalensi penyakit kardiometabolik. WHO menyatakan bahwa obesitas merupakan masalah serius yang kompleks yang dialami oleh segala kelompok umur, mulai dari anak - anak, dewasa sampai lansia. Obesitas harus segera ditangani karena berpotensi menjadi suatu masalah kesehatan (1). Pada penderita obesitas yang memiliki Indeks Masa Tubuh (IMT) $>30 \mathrm{~kg} / \mathrm{m} 2$ akan meningkatkan risiko Penyakit Jantung Koroner (PJK), baik pada laki - laki maupun perempuan. American Heart Association (AHA) mengklasifikasikan obesitas sebagai faktor risiko terjadinya penyakit jantung koroner. Seseorang dengan Obesitas sentral (upper body obesity) akan mudah terkena risiko penyakit jantung dan penyakit metabolik lain yang dikenal sebagai sindrom metabolik dibandingkan dengan obesitas ginoid (lower body obesity) sangat kecil akan risiko terjadinya penyakit metabolik dan jantung koroner.

Tujuan: Tujuan penelitian untuk mengetahui gambaran perilaku masyarakat dilihat dari sudut pandang aktivitas fisik yang menjadi salah satu penyebab kejadian obesitas di Kota Salatiga.

Metode: Jenis penelitian yang digunakan dalam penelitian ini adalah deskriptif kuantitatif dengan pendekatan observasi. Populasi dalam penelitian ini adalah masyarakat yang pernah memeriksakan diri ke Puskesmas Sidorejo Kidul, masing - masing berasal dari lingkup wilayah kerja Puskesmas Sidorejo Kidul. Kriteria inklusi yang diterapkan adalah: 1) masyarakat yang tinggal di wilayah kerja puskesmas sidorejo kidul, 2) berusia 40 tahun ke atas, 3) IMT lebih dari 27,0 .variabel yang dipelajari dalam penelitian ini adalah intensitas aktivitas fisik dan IMT. Instrumen yang dipakai untuk mengukur intensitas aktivitas fisik adalah Global Physical Activity Questionnaire (GPAQ). Wawancara dilakukan untuk mengidentifikasi pemahaman masyarakat yang ada di wilayah kerja Puskesmas Sidorejo Kidul terhadap obesitas dan aktivitas fisik.

Hasil: Setelah semua data terkumpul, hasil penelitian dilakukan dengan menganalisis data dengan reduksi data, penyajian data, penarikan simpulan, dan verifikasi. Setelah semua data terkumpul hasil penelitian dilakukan dengan cara analisis data dilakukan dengan reduksi data, penyajian data, kesimpulan, dan verifikasi.

Kesimpulan: Aktivitas fisik para lansia yang berada di wilayah kerja puskesmas sidorejo kidul kota salatiga, berdasarkan penghitungan Global Physical Activity Questionnaire (GPAQ) termasuk dalam kategori sedang $50 \%$ dengan aktivitas fisik yang umumnya dilakuan oleh Ibu Rumah Tangga (IRT) seperti menyapu, mengepel, masak, dan mencuci. Sebanyak 15\% lansia berada dalam kategori aktifitas fisik rendah dan sisanya termasuk dalam kategori tinggi $35 \%$.

Kata kunci: Aktivitas fisik, Obesitas.

\section{Pendahuluan}

Obesitas merupakan salah satu masalah kesehatan yang berkaitan dengan prevalensi penyakit kardiometabolik. WHO menyatakan bahwa obesitas merupakan masalah serius yang kompleks yang dialami oleh segala kelompok umur, mulai dari anak - anak, dewasa sampai lansia. Obesitas harus segera ditangani karena berpotensi menjadi suatu masalah kesehatan (1). Pada penderita obesitas yang memiliki Indeks Masa Tubuh (IMT) $>30 \mathrm{~kg} / \mathrm{m}^{2}$ akan meningkatkan risiko Penyakit Jantung Koroner (PJK), baik pada laki - laki maupun perempuan. American Heart Association (AHA) mengklasifikasikan obesitas sebagai faktor risiko terjadinya penyakit jantung koroner. Seseorang dengan Obesitas sentral (upper body obesity) akan mudah terkena risiko penyakit 
jantung dan penyakit metabolik lain yang dikenal sebagai sindrom metabolik dibandingkan dengan obesitas ginoid (lower body obesity) sangat kecil akan risiko terjadinya penyakit metabolik dan jantung koroner(2).

Di Negara Indonesia prevalasi obesitas sentral sebesar $18,8 \%$ dari $19,1 \%$ prevalasi obesitas umum. Berdasarkan hasil RISKESDAS tahun 2013, Provinsi Nusa Tenggara Timur memiliki prevalasi obesitas yang paling rendah dengan angka $6,2 \%$ dan yang tertinggi di Sulawesi Utara dengan angka 24,0\%(3). Himpunan Studi Obesitas Indonesia (HISOBI) tahun 2004 meneliti tentang prevalansi obesitas menemukan adanya prevalansi obesitas sentral lebih banyak dari pada obesitas umum dengan prevalansi wanita $11,2 \%$ sedangkan pria $9,6 \%$ mengalami obesitas umum. Pada kelompok obesitas sentral ditemukan prevalansi obesitas lebih tinggi pada pria sebanyak $41,2 \%$ dan $53,3 \%$ pada wanita. Di Indonesia kelompok dengan karakteristik obesitas sentral berada dalam rentang usia $45-54$ tahun sebanyak $27,4 \%(2)$.

Penduduk usia di atas 15 tahun di Jawa Tengah, sebanyak $18,4 \%$ mengalami obesitas sentral. Sebanyak 15 kabupaten/kota dari 35 kabupaten/ kota di Jawa Tengah, angka prevalansi obesitas sentral lebih tinggi dibandingkan dengan angka prevalansi di provinsi. Penderita obesitas sentral di Kabupaten Surakarta berada paling tinggi dengan angka prevalansi sebanyak $34,7 \%$, sedangkan angka terendah berada di Kabupaten Purworejo sebesar $18,5 \%$, sementara Kota Salatiga berada sebesar 23,3\%. Dilihat dari kelompok usia, prevalensi obesitas sentral paling tinggi berada pada kisaran kelompok usia $45-54$ tahun sebanyak $25,1 \%$ sedangkan yang terendah terdapat pada kelompok usia 15 - 24 tahun tahun sebanyak 8,1\%. Angka prevalansi penderita obesitas sentral lebih banyak diderita oleh perempuan sebanyak $28,4 \%$, sedangkan pada laki - laki sebanyak $7,2 \%$ sama halnya dengan obesitas umum(3).

Semakin banyak makanan yang masuk tanpa memperhatikan aspek gizi dan menurunnya aktivitas fisik dapat mengakibatkan terjadinya obesitas. Berbagai penelitian menyatakan bahwa beberapa faktor risiko obesitas sentral yang kerap ditemui yaitu konsumsi alkohol, riwayat merokok, tingginya asupan makanan, dan kurangnya aktivitas fisik. Selain itu, status sosial ekonomi, sedentary life style, dan kemajuan teknologi, sangat mempengaruhi faktor risiko kejadian obesitas (2). Ketersediaan dan kemudahan akses transportasi, teknologi, dan fasilitas publik merupakan beberapa pendukung kegiatan menetap (sedentary) yang di dalamnya terdapat perilaku duduk seperti rekreasi, angkutan umum, dan termasuk menonton televisi, mengendarai mobil, bekerja, maupun bermain di komputer. Beberapa kegiatan tersebut dapat menyebabkan rendahnya aktivitas fisik.(2)

Arti dari aktivitas fisik yaitu segala bentuk gerak tubuh yang dihasilkan otot rangka dan menghasilkan pengeluaran energi. Dalam setiap aktivitas yang dilakukan digolongkan dalam tiga kategori yaitu ringan, sedang, dan tinggi. Lama intensitas ketika melakukan aktivitas fisik yang dilakukan dan kerja otot membutuhkan energi yang berbeda beda. Menurut analisa WHO, aktivitas fisik dan berat badan adanya hubungan yang saling berkaitan berbagai macam penyakit kronis dan secara menyeluruh mengakibatkan kematian secara global(4). Aktivitas fisik memberikan banyak manfaat kesehatan terutama untuk penderita obesitas karena penderita obesitas akan berisiko terkena penyakit metabolik dan kardiovaskuler. Beberapa penelitian menunjukkan bahwa aktivitas fisik memberikan manfaat pada individu yang mengalami masalah obesitas antara lain peningkatan kualitas hidup(5).

Berkurangnya aktivitas gerak dapat disebabkan oleh pertambahan usia akibat penurunan massa otot dalam tubuh. Apabila massa otot menurun, maka akan mengakibatkan penurunan metabolisme. Bila asupan nutrisi tidak berkurang, maka akan mengakibatkan bertambah banyaknya energi di dalam tubuh, sehingga berisiko memunculkan kejadian obesitas. Pada orang dewasa jika melakukan aktivitas fisik cukup maka akan mengurangi berbagai penyakit yaitu risiko hipertensi, penyakit jantung koroner, stroke, diabetes, dan kanker. Banyak penelitian yang dilakukan menemukan adanya hubungan aktivitas fisik dengan kejadian obesitas saling berkaitan, yakni semakin banyak aktivitas yang dilakukan dengan intensitas yang tinggi, maka risiko obesitas akan semakin rendah (6). 
Penelitian mengenai aktivitas fisik dan obesitas sudah dilakukan, namun penelitian tersebut belum dilakukan di Kota Salatiga. Peneliti tertarik untuk mengkaji gambaran aktivitas fisik masyarakat yang mengalami obesitas di Kota Salatiga, khususnya di wilayah kerja Puskesmas Sidorejo Kidul. Melalui penelitian ini diharapkan dapat mengetahui gambaran perilaku masyarakat dilihat dari sudut pandang aktivitas fisik yang menjadi salah satu faktor risiko penyebab kejadian obesitas di Kota Salatiga.

\section{Metode}

Jenis penelitian yang digunakan dalam penelitian ini adalah deskriptif kuantitatif dengan pendekatan observasi. Penelitian dilakukan di wilayah kerja Puskesmas Sidorejo Kidul, Kota Salatiga meliputi Sidorejo Kidul, Tingkir Tengah, Tingkir Lor, Kalibening, Kutowinangun Lor, Kutowinangun Kidul, dan Gendongan. Penelitian dilaksanakan pada bulan Februari - April 2018. Populasi dalam penelitian ini yaitu masyarakat yang pernah memeriksakan diri ke Puskesmas Sidorejo Kidul, masing - masing berasal dari lingkup wilayah kerja Puskesmas Sidorejo Kidul. Kriteria inklusi yang diterapkan adalah masyarakat yang tinggal di wilayah kerja Puskesmas Sidorejo Kidul, berusia 40 tahun ke atas, dan IMT menyatakan lebih dari 27,0 . Variabel yang digunakan dalam penelitian ini adalah intensitas aktivitas fisik dan IMT. Instrumen yang dipakai untuk mengukur intensitas aktivitas fisik yaitu Global Physical Activity Questionnaire (GPAQ) (7). GPAQ merupakan instrumen untuk mengukur aktifitas fisik yang dikembangkan oleh WHO dan kuesioner untuk mengetahui intensitas aktivitas fisik yang kemudian akan digolongkan ke dalam tingkat ringan, sedang, atau tinggi. Wawancara dilakukan untuk mengidentifikasi pemahaman masyarakat yang ada di wilayah kerja Puskesmas Sidorejo Kidul terhadap obesitas dan aktivitas fisik. Analisa data dilakukan dengan tahapan reduksi data, penyajian data, penarikan kesimpulan, dan verifikasi.

\section{Hasil}

Karakteristik responden dilihat dari segi usia dibagi menjadi tiga kategori, masing-masing diperoleh hasil bahwa lebih banyak responden yang masuk dalam kategori umur $>60$ Tahun (69\%), terendah adalah responden yang masuk ke dalam kategori usia $40-49$ tahun (9\%), sedangkan yang masuk dalam kategori umur 50 - 59 tahun dengan presentase 23\%. Berdasarkan kategori jenis obesitas, sebagian besar responden termasuk ke dalam kelompok obesitas tingkat I (55,4\%), sedangkan responden yang termasuk ke dalam kelompok obesitas II dan III masing-masing sebesar $40.5 \%$ dan $4.05 \%$.

Dilihat dari aspek tingkat pendidikan, sebanyak 59 responden mengenyam pendidikan sekolah mulai dari jenjang SD hingga perguruan tinggi. Sebanyak 34\% diantaranya hanya mampu menamatkan hingga jenjang SD, sedangkan $15 \%$ lainnya pada jenjang SMP, 28.3\% pada tingkat SMA, dan hanya 2 orang responden yang mampu menempuh pendidikan hingga jenjang perguruan tinggi. Namun terdapat sekitar 20,2\% responden yang mengaku tidak bersekolah. Dilihat dari aspek pekerjaan, responden yang paling banyak dijumpai yaitu Ibu Rumah Tangga (IRT) sejumlah 32 orang (43.2\%), sedangkan sisanya tersebar pada jenis pekerjaan wiraswasta, guru / karyawan, pensiunan, dan bahkan sudah pensiun. Perolehan penghasilan bulanan pun beragam, namun lebih dari $43 \%$ responden memiliki penghasilan $<\mathrm{Rp}$ 1.000.000-.

Melalui penjaringan data riwayat penyakit, hipertensi merupakan jenis penyakit yang kerap ditemui pada kelompok responden penelitian ini. Sebanyak 30\% responden mengaku memiliki riwayat penyakit hipertensi. Jenis penyakit lain yang saat ini sedang dirasakan oleh para responden dan dianggap sebagai penyakit turunan lainnya adalah DM, asam urat, kolesterol, jantung, dan asam lambung. Namun, sekitar 35\% responden menyatakan bahwa dirinya tidak memiliki riwayat penyakit apapun. Berdasarkan jenis aktivitas fisiknya, 50\% responden tergolong ke dalam kelompok dengan jenis aktivitas sedang. Sekitar $35 \%$ dan $15 \%$ responden masing-masing termasuk ke dalam kelompok aktivitas tinggi dan rendah. 
Tabel 1 | Karakteristik responden di wilayah kerja Puskesmas Sidorejo Kidul Karakteristik Responden

Jumlah Persentase

(n)

Jenis Kelamin

$\begin{array}{lcc}\text { Pria } & 3 & 4,05 \\ \text { Wanita } & 71 & 95,95\end{array}$

Usia

\begin{tabular}{|lcc|}
\hline 40-49 Tahun & 6 & 8,1 \\
\hline 50-59 Tahun & 17 & 23 \\
\hline >60 Tahun & 51 & 68,9 \\
\hline
\end{tabular}

Jenis Obesitas

\begin{tabular}{llcc} 
Obesitas I & 41 & 55,4 \\
\hline Obesitas II & 30 & 40,5 \\
\hline Obesitas III & 3 & 4,05
\end{tabular}

Pendidikan

\begin{tabular}{lcc} 
SD & 25 & 33,8 \\
\hline SMP & 11 & 14,9 \\
SMA & 21 & 28,4 \\
\hline Perguruan Tinggi & 2 & 2,7 \\
\hline Tidak Sekolah & 15 & 20,3
\end{tabular}

Penghasilan

$\begin{array}{lcc}<1.000 .000 & 32 & 43,2 \\ 1.000 .000-1.500 .000 & 30 & 40,5 \\ 1.500 .000-2.000 .000 & 6 & 8,1 \\ >2.000 .000 & 6 & 8,1\end{array}$

Riwayat Penyakit

\begin{tabular}{lcc}
\hline Hipertensi & 22 & 29,7 \\
\hline DM & 4 & 5,4 \\
\hline Asam Urat & 12 & 16,2 \\
\hline Kolesterol & 5 & 6,8 \\
\hline Jantung & 4 & 5,4 \\
\hline Asam Lambung & 1 & 1,4 \\
\hline Tidak Ada & 26 & 35,1 \\
\hline
\end{tabular}

Tingkat Aktivitas Fisik

\begin{tabular}{lcc} 
Rendah & 11 & 14,9 \\
\hline Sedang & 37 & 50 \\
\hline Tinggi & 26 & 35,1
\end{tabular}

(\%)

lebih sedikit dibandingkan dengan wanita. Lemak tubuh dan berat badan pada laki - laki dan wanita yang normal antara 18 - 23\% untuk laki - laki, dan wanita 25 - 30\%. Jika wanita memiliki lemak tubuh melebihi dari 30\%, maka dianggap mengalami obesitas, sedangkan laki-laki ditetapkan ambang batas 25\%. Secara umum, apabila mempunyai berat badan $20 \%$ lebih tinggi dari nilai tengah kisaran berat badannya yang normal maka seseorang tersebut mengalami kejadian obesitas(8).

Pengetahuan yang tinggi dapat mempengaruhi latar belakang pendidikan seseorang. Tingkat pendidikan seseorang yang semakin tinggi, berdampak pada tingkat pemahaman seseorang yang akan semakin baik tentang suatu konsep yang dipelajari. Pemahaman tersebut akan membentuk cara dan pola berpikir seseorang, sehingga dapat melakukan analisa yang tajam dan mampu memberikan persepsi yang baik(9). Dalam penelitian ini sebagian besar responden mengenyam pendidikan hingga jenjang SD yaitu sebesar 34\%, sedangkan PT (Perguruan Tinggi) sebanyak $2,7 \%$. Kondisi tersebut dapat berdampak pada pengetahuan keluarga tentang pentingnya pemilihan jenis makanan serta upaya untuk menjaga pola makan yang sehat dan bergizi. Banyaknya pengetahuan tentang gizi responden yang cukup dapat juga diperoleh dari pekerjaan responden. Semakin banyak bersosialisai dengan orang lain maka akan membuat pengetahuan responden semakin luas. Suhartono mengungkap-kan bahwa 
otoritas kesaksian orang lain bisa menjadi sumber pengetahuan seseorang, semakin banyak bersosialisasi dengan orang lain maka akan semakin banyak juga pengetahuan yang di peroleh(10). Mayoritas responden dalam penelitian ini berprofesi sebagai Ibu Rumah Tangga (IRT), sehingga menyebabkan kurangnya interaksi responden dengan orang lain dan pengetahuan responden tentang gaya hidup sehat sangat berkurang. Umumnya, aktivitas sehari - hari ibu rumah tangga berskala sedang.

Keadaan sosial ekonomi keluarga dapat dilihat dari pendidikan, penghasilan, status pekerjaan, dan jumlah anggota keluarga. Kelas sosial dan status sosial ekonomi mempengaruhi prevalensi terjadinya obesitas. Aritonang berpendapat faktor terjadinya obesitas salah satunya dari penghasilan (pendapatan) keluarga. Semakin meningkatnya pendapatan dalam keluarga, maka bepengaruh terhadap pemilihan bahan makanan yang dikonsumsi setiap harinya. Kualitas makanan yang dibeli perlu tetap diperhatikan agar memenuhi aspek higienitas dan beizi. Pemilihan bahan makanan yang kerap dikonsumsi oleh para responden mengarah pada bahan dan jenis makanan yang berminyak, mengandung lemak, cepat saji, dan bahan lainnya yang dapat juga mengakibatkan obesitas(11).

Obesitas juga merupakan salah satu faktor resiko terjadinya hipertensi(12). The Framingham Heart Study menyatakan terdapat adanya hubungan antara hipertensi dengan obesitas. Faktor risiko hipertensi pada pria mencapai $78 \%$, sedangkan pada wanita $65 \%$ berhubungan erat dengan obesitas(13). Rahmouni et al. juga mengungkapkan adanya hubungan erat antara obesitas dengan kejadian hipertensi(14). Dalam penelitian ini terdapat riwayat penyakit Hipertensi sebanyak 22 orang.

Risiko terjadinya obesitas akan semakin berkurang jika aktivitas fisik dilakukan secara rutin dengan intensitas fisik yang tinggi dan mengurangi porsi makanan yang di konsumsi. Olahraga merupakan contoh aktivitas fisik yang terstruktur, direncanakan, dan dilakukan berkelanjutan bertujuan dapat meningkatkan kualitas kesehatan dan mempertahankan aspek kebugaran. Jika aktivitas fisik yang dilakukan semakin berat, maka risiko terjadinya obesitas akan semakin rendah(15). Apabila aktivitas fisik yang dilakukan dengan intensitas yang rendah dan semakin banyak asupan makanan yang di konsumsi maka secara tidak langsung akan risiko terkena kejadian kegemukan dan obesitas. Dalam upaya menjaga dan meningkatkan kesehatan lansia, para responden dapat menambah durasi aktivitas fisik maksimal 45 menit setiap harinya, menambah jenis aktivitas fisik antara lain joging, senam dan renang serta menambah frekuensi aktivitas fisik maksimal 3 kali seminggu.

\section{Kesimpulan}

Aktivitas fisik para lansia yang berada di wilayah kerja puskesmas sidorejo kidul kota salatiga, berdasarkan penghitungan Global Physical Activity Questionnaire (GPAQ) termasuk dalam kategori sedang $50 \%$ dengan aktivitas fisik yang umumnya dilakuan oleh Ibu Rumah Tangga (IRT) seperti menyapu, mengepel, masak, dan mencuci. Sebanyak $15 \%$ lansia berada dalam kategori aktifitas fisik rendah dan sisanya termasuk dalam kategori tinggi $35 \%$.

\section{Bibliografi}

1. Yuhanda DSF. Hubungan Pola Makan Dan Aktivitas Fisik Dengan Kejadian Obesitas Pada Anak Di Sdn Nusawangi 3 Desa Nusawangi Kecamatan Cisayong Kabupaten Tasikmalaya. 2015;41.

2. Wira Gotera, Suka Aryana, Ketut Suastika, Anwar Santoso TK. Hubungan Antara Obesitas Sentral Dengan Adiponektin Pada Pasien Geritari Dengan Penyakit Jantung Koroner. J Penyakit Dalam. 2014;7(1):1-5.

3. RISKESDAS. Penyakit yang ditularkan melalui udara. Jakarta Badan Penelit dan Pengemb Kesehat Dep Kesehat Republik Indones. 2013;(Penyakit Menular):103.

4. Istiqamah N, Sirajuddin S, Indriasari R. Hubungan Pola Hidup Sedentarian dengan Kejadian Obesitas Sentral pada Pegawai Pemerintahan di Kantor Bupati Kabupaten Jeneponto. Fkm Unhas. 2013;1-13.

5. Penelitian B, Kesehatan DP, Kesehatan D, Tahun R, li 2009, Pengantar K. Laporan Hasil Riset Kesehatan Dasar (Riskesdas) Provinsi Jawa Tengah Tahun 2007. 2009;

6. Habut MY, Nurmawan IPS, Wiryanthini IAD. Hubungan Indeks Massa Tubuh dan Aktivitas Fisik 
terhadap Keseimbangan Dinamis pada Mahasiswa Fakultas Kedokteran Universitas Udayan. Maj IIm Fisioter Indones. 2015;2(1):45-51.

7. Fiona C. Bull, Tahlia S. Maslin, and Timothy Armstrong. Global Physical Activity Questionnaire (GPAQ). Journal of Physical Activity and Health. 2009;6:790-804.

8. Cena H, De Giuseppe R, Biino G, Persico F, Ciliberto A, Giovanelli A, et al. Evaluation of Eating Habits and Lifestyle in Patients With Obesity Before and After Bariatric Surgery: Asingle Italian Center Experience. Springerplus. 2016;5(1):1467.

9. Widiantini, W. ZT. Aktifitas Fisik, Stres, Dan Obesitas Pada Pegawai Negeri Sipil. J Kesehat Masy Nas. 2014;8(7):329-36.

10. Budiyanto MA. Diet Therapy Pada Obeistas. Madang: Gizi dan Kesehatan. UMM Press; 2002. 47-55 p.

11. Notoatmodjo S. Pendidikan dan Perilaku Kesehatan. Jakarta: Asdi Maha Surya; 2005.

12. Suhartono S. Filsafat IImu Pengetahuan. Yogyakarta: Ar Ruzz; 2008.

13. Hadi SM, Sulityowati E M. Hubungan Pendapatan Perkapita, Pengetahuan Gizi lbu dan Aktivitas Fisik dengan Obesitas Anak Kelas 4 dan 5 di SD $\mathrm{Hj}$. Kesehat Masy Indones. 2005;

14. Natalia, Diana; Hasibuan P; H. Hubungan Obesitas Dengan Kejadian Hipertensi di Kecematan Sintang, Kalimatan Barat. Cdk. 2015;42(5):336-9.

15. Wolk R, Shamsuzzaman ASM SV. Obesity Sleep Apnea and Hypertension. 2003. 42:1067. 